\title{
Disciplina, resistências e o trabalho em orquestras sinfônicas
}

\author{
Discipline, resistance and work in symphonic orchestras
}

\section{Disciplina, resistencia y trabajo en orquestas sinfónicas}

ORCID: 0000-0002-1803-2356

Eric Campos Alvarenga

E-mail: ericsemk@gmail.com

Paulo de Tarso Ribeiro de Oliveira Universidade Federal do Pará (UFPA), Belém - PA/Brasil

E-mail: pttarso@gmail.com

Flávia Cristina Silveira Lemos

Universidade Federal do Pará (UFPA), Belém - PA/Brasil

ORCID: 0000-0003-4951-4435

E-mail: flaviacslemos@gmail.com

\begin{abstract}
Resumo
Este artigo é um ensaio busca analisar relações entre as orquestras sinfônicas e a disciplina por meio dos estudos de Michel Foucault. A ideia central é que orquestras sinfônicas materializam práticas de produção de uma racionalidade pautada em docilidade política, produtividade e corpos disciplinados para um trabalho meticuloso da música com atenção detalhada. Trata-se de texto teórico e analítico, baseado em alguns operadores analíticos de Michel Foucault. O artigo é resultante de uma pesquisa maior finalizada, na Pós-Graduação em Psicologia. É possível afirmar que a música orquestral é uma maneira de inventar no trabalho e, simultaneamente, de resistir às disciplinas docilizadoras, em termos de um campo dinâmico de forças múltiplas de saberes e poderes. Só há disciplina quando temos liberdade concomitantemente.
\end{abstract}

Palavras-chaves: Orquestra sinfônica; Trabalho; Disciplina; Resistência; Michel Foucault.

\begin{abstract}
Resumen
Este artículo es un ensayo que busca analizar las relaciones entre las orquestas sinfónicas y la disciplina a través de los estudios de Michel Foucault. La idea central es que las orquestas sinfónicas materializan prácticas de producción de una racionalidad basada en la docilidad política, la productividad y los cuerpos disciplinados para un trabajo meticuloso de la música con una atención detallada. Es un texto teórico y analítico, basado en algunos operadores analíticos de Michel Foucault. El artículo es el resultado de una investigación más amplia realizada en el Programa de Posgrado en Psicología. Es posible afirmar que la música orquestal es una forma de inventar en el trabajo y, a la vez, de resistir disciplinas docilizantes, en términos de un campo dinámico de múltiples fuerzas de conocimiento y poderes. Hay disciplina solo cuando tenemos libertad al mismo tiempo.
\end{abstract}

Palabras clave: Orquesta sinfónica; Trabajo; Tema; Resistencia; Michel Foucault.

\begin{abstract}
This article is an essay seeking to analyze relations between symphonic orchestras and the discipline through the studies of Michel Foucault. The central idea is that symphonic orchestras materialize practices of production of a rationality based on political docility, productivity and disciplined bodies for a meticulous work of music with detailed attention. It is a theoretical and analytical text, based on some analytical operators by Michel Foucault. The article is the result of a larger research completed, in the Graduate Program in Psychology. It is possible to affirm that orchestral music is a way to invent at work and, simultaneously, to resist docilizing disciplines, in terms of a dynamic field of multiple forces of knowledge and powers. There is discipline only when we have freedom concurrently.
\end{abstract}

Keywords: Symphonic orchestra; Job; Subject; Resistance; Michel Foucault. 


\section{Introdução}

Este artigo busca analisar as práticas disciplinares no trabalho dos músicos de orquestras, de acordo com algumas contribuições de Michel Foucault a respeito do poder disciplinar e da submissão dos corpos no trabalho, simultaneamente, procura-se pensar as resistências no bojo das forças em uma dinâmica móvel e relacional no próprio âmbito do poder-saber disciplinar. Vale ressaltar como o trabalho da música, em uma modalidade de orquestra pode acionar mecanismos meticulosos e rígidos de aprendizagem e exercícios cotidianos marcados por ensaios e exigências consideráveis.

O poder disciplinar era usado nos monastérios católicos, no período medieval e pelos metodistas ingleses. A partir do século XVI, a disciplina passa a ser utilizada nas chamadas casas de trabalho forçado. Em seguida, durante o século XVII generaliza-se o poder disciplinar como mecanismo de saber e poder nas mais diferentes organizações, equipamentos e em meio aberto. Amplia-se a disciplina como prática cotidiana, em uma sociedade que começa a constituir a disciplina como modo de viver, de pensar, de agir, de se relacionar e de existir.

O poder disciplinar materializa o controle do tempo, do espaço, da vigilância hierárquica, da sanção normalizadora e do exame, submetendo os corpos às técnicas que visam criar obediência e produtividade. A disciplina não é em si negativa, pois permite aprendizagens, trabalho organizado, normalizações de condutas e regras mediadoras da cultura e da linguagem. Ou seja, com efeito, há uma positividade na disciplina para o fazer a vida caminhar com alguma tentativa de regularidade. Neste aspecto, Foucault (1996; 1999) diferencia disciplina de opressão, de repressão, de violência e de dominação. Ao contrário das análises clássicas do poder que o definiam como negativo pela ideia de proibição e exclusão, Foucault (1979; 1999) destacou a dimensão de inclusão do poder-saber disciplinar e como esta é mais prescritiva do que proibitiva.
É no bojo deste processo que Foucault (1996; 2008a) ressaltou que a disciplina opera por curvas de normalidade inclusivas sempre com vistas a aumentar a produção nas atividades realizadas, criar a docilidade política, expandir habilidades de fazeres no trabalho regrados pela negociação das normas disciplinares. Por isto, só há disciplina quando há liberdade e neste ponto que se generaliza na modernidade da emergência do Estado Democrático de Direito. Assim, a disciplina se torna um mecanismo importante para as artes, as expressões culturais, os estudos, a organização do trabalho, os esportes, os cuidados em saúde, as ciências, a economia, a justiça, a assistência social, a escolarização e até mesmo para a chamada qualidade de vida enquanto modo de existência.

Portanto, o poder disciplinar permitiu o desenvolvimento de uma série de práticas sociais, no período de industrialização, no deslocamento e relacionamento das pessoas, com a expansão do capitalismo na sociedade liberal que criticava a punição física e defendia as liberdades propostas na Revolução Francesa. A submissão à disciplina passou a ser algo da ordem de poder ganhar benefícios diversos: diplomas, aquisição de conhecimento e cultura, benefícios e promoções no Direito trabalhista, no aumento dos usos das tecnologias, na burocracia das instituições democráticas e representativas e ainda no Direito Internacional (Foucault, 2008b).

Desde a segunda metade do século XIX, em especial, passou a vigorar a disciplina em associação com o governo da vida chamado de biopolítica com certa regularidade, ocorrendo por meio das medicalizações da vida, da cidade, do trabalhador, da família, da infância e da escola. Neste sentido, surge em conjunto a criação de saberes das denominadas ciências biológicas e da saúde, das ciências humanas e sociais (Foucault, 1988).

A disciplina, na medida em que se torna mais ágil e volátil passa a funcionar como controle em meio aberto, se desbloqueando dos muros institucionais para materializar-se como mecanismo. O panoptismo foi justamente esse 
jogo que permitiu combinar e articular a disciplina com as estratégias de controle com mais velocidade e modulação rápida, quase instantânea por meio de subjetividades flexíveis (Deleuze, 1992).

$\mathrm{Na}$ atualidade, na virada do século $\mathrm{XX}$ para o XXI, é possível afirmar que a disciplina gerou uma sociedade de considerável segurança. Cada vez mais, houve um acoplamento dos dispositivos de segurança com as disciplinas, os quais relacionam liberdade e seguridade, investem na produção do empresário de si e do outro, além do que, acionam capturas e apropriações de capital social, humano e cultural (Foucault, 2008a; 2008b).

A música e a educação musical foram e têm sido um modo de compartilhar a cultura e as artes, de educar corpos e subjetividades, de produzir reflexão e passou a ser um instrumento de diversão na indústria da cultura. A disciplina proposta pelo ensino musical se tornou um mecanismo bastante utilizado para submeter politicamente e forjar corpos úteis e dóceis, nos últimos séculos. A educação musical se tornou parte de um currículo preocupado com a ideia de civilização contra uma suposta barbárie. Todavia, em certas realidades, a música e o ensino da mesma ganharam nuances autoritárias bem como de protesto e insurreição política, social, cultural, subjetiva e econômica. A música e o ensino da mesma também podem produzir resistências e transformações diversas no trabalho, na política, na economia, na sociedade, na subjetividade, no trabalho e na cultura.

\section{I - Prelúdio}

Segundo Feitosa (2010), é possível afirmar que há três tipos de orquestra: de câmara, filarmônica e sinfônica. Uma orquestra pode ser mantida por, porém, predominam as entidades públicas como mantenedoras. $\mathrm{O}$ trabalho nas orquestras sinfônicas demanda considerável disciplina no aprendizado permanente da música, nos ensaios e nas apresentações. Portanto, os modos de ser, de sentir, de agir, de viver e se relacionar de um(a) musicista enquanto trabalhador(a) de uma orquestra sinfônica é uma atividade marcada pelo poder-saber disciplinar em diversos aspectos.

Para Gustavo Borchert (2009), a orquestra sinfônica moderna possui um conjunto de valores e práticas que povoam os discursos de variados grupos, comunidades e organizações como uma instituição composta pela cultura erudita, sendo caracterizada por uma perspectiva elitizada da música. Com efeito, esta visão se relaciona a rituais disciplinares e culturais que constituem as apresentações em grandes teatros e nos programas acadêmicos dos conservatórios de música, desde o século XIX. Mas, pode ser fabricada pela noção de uma classificação da música de orquestra como clássica e pelas vestimentas de musicistas, custo das aulas e dos instrumentos, longo período de aprendizado e apreciação por arranjos, acordes, melodias e partituras complexas.

Os rituais disciplinares operam por mecanismos de controle dos corpos no tempo e espaço, por vigilâncias hierárquicas, exames constantes e sanções normalizadoras. Estes rituais estão presentes na formação, trabalho e apresentação de musicistas das orquestras sinfônicas. Historicamente, as grandes sinfônicas emergem em um contexto de expansão industrial no século XIX, o que trará efeitos à sua constituição disciplinar também. Assim como as novas fábricas, as orquestras sinfônicas apresentarão mudanças em sua organização e modos de subjetiva, de fabricar existências e relações. Tais transformações compartilham relações com o panorama traçado por Michel Foucault, em Vigiar e Punir, em que situa o poder disciplinar.

Certamente, ressalta-se que os modos de organização do trabalho de musicistas das orquestras sinfônicas implicam em maneiras específicas de lidar com o corpo e com a vida, gerindo-a de forma a expandir a saúde e a seguridade, na medida em que a cultura erudita musical postula a prática cotidiana de exercícios metódicos e minuciosos, em consonância com modalidades de estratégias de 
grupo e de segmentos populacionais, em sua totalidade. Ainda é importante notar que a disciplina é articulada com o controle e o dispositivo de segurança por meio de modulações mescladas com as outras formas de exercício de poder-saber, de sorte a incrementar uma política securitária. As orquestras sinfônicas estão vinculadas às técnicas descritas neste texto de funcionamento do poder disciplinar.

\section{II - As relações de poder, saber e de subjetivação que disciplinam, expandem a vida e que forjam segurança}

De acordo com Passos (2008), a questão da analítica do poder será um dos objetos das pesquisas históricas de Michel Foucault, a partir do início da década de 1970. Nesse período, o autor buscava estudar os mecanismos de poder e de saber, agenciados em diferentes modos de as relações de poder se materializarem. Assim, poder é uma dinâmica, uma relação móvel e um exercício e não um atributo, propriedade, aquisição, transferência ou localidade, nem é apenas efeito de uma prática econômica (Foucault, 1999a).

Por isto, Deleuze (2005) ressalta que o poder, ao invés de atributo, é relação: "[...] a relação de poder é o conjunto de relações de forças, que passa tanto pelas forças dominadas quanto pelas dominantes, ambas constituindo singularidades" (p. 37). O poder não tem essência, pois ele é operatório. Uma analítica do poder considera táticas, normas, estratégias e forças em multiplicidade. $O$ poder não é um lugar e um dizer não, na medida em que prescreve ao invés de proibir.

Para Foucault, as relações de poder são diagonais e heterogêneas, articulam saberes, modulam corpos e ultrapassam os muros, os Estados, as classes, a economia, a soberania jurídica e chega até o nível local do corpo a corpo e da resistência microfísica (Foucault, 1979). Na obra Vigiar e Punir, Foucault (1999a) focaliza a relação entre poder e saber na dimensão de uma analítica e não de uma teoria do poder. Há linhas visíveis e dizíveis, formando o diagrama de forças. Sendo assim, pode-se afirmar que não há relação de poder sem que se produza um campo de saber, concomitantemente. Ambos, agem em rede e em correlação.

Segundo Deleuze (2005), a disciplina é um tipo de poder e vai tomando mais forma a partir de Vigiar e Punir. É nela que Foucault, ao escrever sobre as sociedades modernas, aponta que estas podem ser definidas como "disciplinares": de acordo com Passos (2008), nas sociedades modernas, podia ser visto um poder atuante, que constituía a modernidade e era contrário a um poder de tipo repressivo. Este poder era o disciplinar. Ele age conforme estratégias, táticas e técnicas silenciosas de adestramento. É algo como uma espécie de ajustamento físico, político e moral dos corpos.

Deleuze (2005) destaca que não deveríamos pensar a disciplina apenas como uma instituição ou um aparelho, pois ela é poder, é tecnologia: é algo que passa pelas instituições e aparelhos, de maneira que, investido nestes, aquela será responsável por reuni-las, torná-las atuantes por mais tempo; irá aglutiná-las e as capacitará com a possibilidade de se atualizarem em novas formas.

No bojo desta problematização, Deleuze (2005) destaca que a subjetividade não é um invólucro, uma interioridade, um psiquismo, um sujeito da consciência, um comportamento social, uma atitude, uma representação ou conjunto de várias representações, uma percepção combinada a outras; para Foucault (Deleuze, 1992), uma dobra que não é interior, nem somente exterior, é resultado provisório de relações de saber e de poder, ligadas aos processos de subjetivação que são múltiplos e singulares. Onde há exercício analítico de forças há também saber e subjetivação. O saber é um conjunto de práticas discursivas, enquanto o poder e a subjetividade são práticas não discursivas. Eles são imanentes e não estão em relação causal e linear, são singulares e dizem das relações em seus arranjos e rupturas dinâmicas e móveis, em exercício entre corpos, em atos de resistência e de assujeitamento permanentes (Foucault, 1999a). 


\section{III - O corpo obediente e útil disciplinado}

Para Foucault (1999a), o começo do uso do corpo como objeto e alvo de poder passa a acontecer a partir da época clássica. É fácil encontrar, nesse período, um foco intenso sobre o corpo como algo que é passível de ser manipulado, modelado, treinado e sujeito à obediência. Essa espécie de manual de um suposto "homem-máquina" foi escrito basicamente em dois grandes contextos. Um deles será chamado pelo autor de anátomometafísico, tendo Descartes como seu principal precursor que seria bastante utilizado e desenvolvido por médicos e filósofos. Já, o segundo será em um âmbito mais técnicopolítico, desenhado com traços de regulamentos militares, escolares, hospitalares e por processos práticos feitos para manipular ou até mesmo corrigir as operações do corpo. A música e o ensino da mesma demandam regularidade de articulações dos estabelecimentos e organizações de ensino, da cultura, da arte, da economia política, da sociabilidade, do lazer e religiosas.

Vemos que são dois registros diferentes que, em um momento, parecem tratar de submissão e utilização dos corpos; já, em outro, há tentativas de explicação de seu funcionamento e de sua composição. Temos, então, um corpo útil e passível de inteligibilidade. E, por aqui, a noção de docilidade atravessará esses dois espaços discursivos. Conforme Foucault (1998), o corpo dócil é aquele que pode ser submetido, utilizado, transformado e aperfeiçoado. Quem trabalha em uma orquestra sinfônica está constantemente submetido à produção aumentada, à performance expandida e à submissão com extrema obediência aos rituais disciplinares dos exercícios e apresentações musicais, tais como os que são realizados em concertos.

Nosso corpo será parte de uma maquinaria de poder. Esta maquinaria o dividirá, o desarticulará para, depois, o recompor. Foucault chamará isso de anatomia política. Nasce, então, algo como uma mecânica do poder e a criação de saberes. Seu grande objetivo é encontrar formas cada vez mais eficazes de dominar os corpos dos outros, não apenas para que façam o que se quer que seja feito, mas também para que se comportem de determinado modo, com determinadas técnicas, segundo certa rapidez, buscando-se certa eficácia. A disciplina aumentará suas forças em termos econômicos de utilidade e também irá diminuí-las em relação a aspectos políticos de obediência. A orquestra é um treino de utilidade e apreciação elitista simultaneamente porque estabelece relações entre um trabalho árduo de treino $\mathrm{e}$ aprendizagem bem como o despertar da sensibilidade de quem prestigia as apresentações sinfônicas de musicistas, em teatros, em parques e casas de cultura.

A disciplina, muitas vezes, exigirá um local específico e fechado: Um lugar protegido onde ela possa reinar absoluta, sem tanta interferência. Posteriormente, nas orquestras, há esse local de reclusão que são as salas de ensaio coletivos dos músicos, como aparece, por exemplo, no filme Ensaio de Orquestra, de Fellini. Nele, vemos um grupo de instrumentistas de uma orquestra local ensaiando em um ambiente fechado e relativamente amplo, onde cabe toda a heterogeneidade de músicos. Um local silencioso, para que barulhos externos não interfiram no trabalho e na concentração de todos ali. Regular sons, o espaço, os tempos, as sequências de atos, a coordenação psicomotora, as posturas, as expressões corporais, as vestimentas, os lugares de cada um com os instrumentos específicos em determinados ritmos e separar o público dos músicos são rituais políticos específicos da disciplina em expansão da utilidade e da produtividade das combinações das forças e das vigilâncias mútuas em efeitos das ações sobre ações, de forças com forças.

Os espaços de apresentação das orquestras sinfônicas podem ser organizados em um conjunto de práticas sociais em que há uma intensa repartição desse certo espaço, de fazer do mesmo um ato de quadriculamento 
permanente. Cada indivíduo é posicionado em seu lugar no grupo de trabalho e de acordo com a instituição música erudita pressupõe na cultura disciplinar. Para Foucault (1996), há uma tentativa de evitar distribuir os espaços em grupos, conforme a produção e o desempenho, de acordo com as habilidades e capacidades, segundo as performances e as composições de instrumentos e níveis de aprendizado.

Com efeito, trata-se de realização uma decomposição das implantações coletivas do trabalho em ato, o que implica em resistências, pois, onde há poder sempre há possibilidade de resistências. Buscar-se-á dividir em quantas parcelas for possível para repartir os corpos, porém, o trabalho não é apenas obediência e submissão, há insurgências e indisciplinas.

A criação acontece também em meio ao trabalho vivo em que a disciplina é tensionada a favor de novas práticas e de uma estética de si e dos outros, ou seja, em um exercício de cuidado de si e dos outros, em meio à coragem de ousar na verdade e na política (Foucault, 2010). Para Schwartz (2000), a dimensão criativa e viva do trabalho como resistência, como cuidado de si e dos outros. O trabalho é uma atividade que produz subjetividade e permite práticas éticas, estéticas e políticas da ordem da potência de invenção, de transformação das realidades, dos valores e das sociabilidades.

Simultaneamente, a disciplina opera resistência e submissão porque onde há poder há resistências. Os usos que podemos fazer do trabalho como força inventiva é também materializado no cotidiano das orquestras sinfônicas e dos trabalhadores que a compõem. $\mathrm{Se}$, a disciplina visa anular efeitos de divisões indecisas, muita perambulação, deserções, vadiagens, aglomerações; também pode operar a criação e o novo, a fabricação de subjetividades libertárias e inventivas.

As disciplinas, organizando as "celas", os "lugares" e as "fileiras" criam espaços complexos: ao mesmo tempo arquiteturais, funcionais $\mathrm{e}$ hierárquicos. São espaços que realizam a fixação e permitem a circulação; recortam segmentos individuais e estabelecem ligações operatórias; marcam lugares e indicam valores; garantem a obediência dos indivíduos, mas também uma melhor economia do tempo e dos gestos. (Foucault, 1999, p. 128).

Para Foucault (1999), todas as práticas de poder disciplinar, tais como: as seriações e repartições contribuem para desfazer confusões supostamente perigosas por terem a chance de produzirem dispersões de forças e insubmissões políticas variadas. A produção passou a ser dividida por etapas. $\mathrm{O}$ processo de trabalho é desenhado em dois nortes: 1- de acordo com suas fases, estágios ou operações elementares e 2- segundo aqueles que o efetuam e os corpos singulares que servem de aplicação. O vigor, a rapidez, a habilidade, a constância, ou seja, cada aspecto da força de trabalho pode ser observado para então ser caracterizado, apreciado, contabilizado e transmitido ao seu "responsável". E será nesse contexto, onde a força de trabalho é analisada em unidades individuais, onde há divisão do processo de produção, que nascerá a organização do trabalho também das orquestras como instituição disciplinar. Aqui, há estreita relação com o que Foucault (1999a) sublinha sobre o "panoptismo". O panóptico é descrito de forma concreta como uma relação óptica não apenas aplicada a uma materialidade visível tal como uma escola, um hospital, uma prisão, entre outros -, mas como coisa que atravessa de maneira geral todas as funções passíveis de serem enunciadas.

O diagrama do panóptico permite, ao mesmo tempo, vigilância mútua na realização das atividades do trabalho de uma orquestra sinfônica, em meio aberto concomitantemente à montagem de diagramas múltiplos $\mathrm{e}$ heterogêneos de forças, as quais podem ser mutantes na correlação que vão sendo estabelecidas em meio às performances do trabalho vivo e em ato da música. O que era disciplina pode se tornar uma dramática a ser problematizada. Uma sinfonia enquanto peça 
musical resulta de intensa disciplina, porém, foge à mesma na medida em que forja sensibilidades, afetos, apreciações e apropriações variadas e em variação dos modos de ser. Neste aspecto que Deleuze (2005) indica o quanto o panóptico é uma máquina de visibilidade e dizibilidade também delineada como uma cartografia, um conjunto de muitas linhas móveis, entrecruzadas e distintas, que são combinadas ao acaso e podem traçar linhas de fuga, resistências às capturas do trabalho morto, de acordo com Schartz (2002).

Assim, o panoptismo mostra-se como uma imposição de certa conduta a alguma multiplicidade humana. Para tal, tentava-se reduzir essa multiplicidade, levando-a para um espaço restrito e impondo-lhe uma conduta, na medida em que havia um seccionamento do espaço-tempo. Nessa função, as formas usadas, como a educação, o tratamento, a punição, entre outras, não eram consideradas. Em acréscimo, tão pouco tinham destaque as substâncias que tomavam corpo nessa aplicação, como os "presos", os "doentes" e "escolares". Procurar-se-á um aumento da qualidade de uso desse tempo. A ideia é formar um tempo cada vez mais útil, sem dar muita chance para desvios, impurezas, defeitos. Um tempo com qualidade "adequada", onde o corpo deve estar totalmente envolvido, compenetrado e aplicado ao seu exercício.

\section{IV - A orquestra disciplinada e o trabalho musical}

O corpo do músico de uma orquestra sinfônica parece também receber esse tratamento disciplinar. Ele também entrará nessa lógica onde perceberemos um predomínio de sua máxima utilização, tanto em quantidade de corpos, quanto em quantidade de utilização destes corpos. Notaremos as orquestras incharem. Muitos músicos agora farão parte das apresentações e ensaios. Eles serão vistos como trabalhadores, terão um salário, serão responsáveis pela produção, assim como os operários fabris. Eles somem. Serão cada vez mais submissos. E, diante de toda essa nova complexidade, será visto o surgimento de uma peça aparentemente fundamental que controlará (e será controlado por) todas as outras: o maestro. São muitos músicos e muitos instrumentos.

Vê-se então ser criada a demanda de alguém que dê certa harmonia e organização, que direcione o andamento do trabalho e o fiscalize, para que haja coesão nessa multidão de sons. O maestro será o líder da orquestra. E um líder silencioso. Não deverá fazer ruído algum. Ele mudará inclusive o desenho dos músicos no palco. Todos estes irão se posicionar de acordo com o líder, já que todos deverão estar de olho em seus movimentos e comandos. Imagem comum para os frequentadores de grandes concertos, os músicos se sentam em volta do regente, posicionados também diante de suas partituras. Um olho no papel, outro no maestro. $\mathrm{Na}$ partitura estão escritas as notas que devem ser tocadas, assim como o tempo exato da execução de cada uma delas. Estarão também presentes: a duração, o ritmo, a altura, a intensidade, entre outras especificidades da obra. Cada músico terá a partitura particular de seu instrumento.

Nela, o compositor expõe como ele elaborou cada parte de sua obra. Entende-se que é fundamental que cada músico a acompanhe, para o adequado funcionamento do conjunto, seja seguindo os escritos que estão ali diante dele, seja no caso daqueles que já praticaram tanto a ponto de tê-la memorizado, seguindo o que foi guardado mentalmente. Nesse contexto, a improvisação mostra-se cerceada em nome da preservação dos arranjos originais. Há uma espécie de ditadura da partitura. Espera-se que os músicos toquem os arranjos tal como eram realizados por seus compositores. Espera-se que o maestro faça esse controle mínimo da execução, que esteja atento a qualquer desvio. $\mathrm{O}$ maestro será o capataz da fábrica/orquestra, atento a cada deslize dos operários/músicos, nas esteiras/palcos de produção.

Neste ponto, esboçaremos outros aspectos das orquestras sinfônicas de acordo com Alberto (2010). Observaremos que é preciso muita aplicação e trabalho para ser 
músico de uma orquestra. Porém, há uma tentativa de se aproximar dela e executar bem a obra de certo compositor. Para isso, é preciso ter horas e horas de dedicação e amar seu trabalho. Em meio a uma conversa entre o personagem principal do romance de Alexandre Dumas, chamado Hoffman, e o mestre Gottlieb Murr, um velho regente de orquestra, podemos ver indícios da extrema exigência imposta aos que tocam esse instrumento clássico. Hoffman conta a Murr que toca violino; este imediatamente começa a questioná-lo se ao menos sabe o que é o violino.

Oh, o violino! Você sabe, profanador infeliz, que esse instrumento esconde sob sua simplicidade quase miserável os mais inesgotáveis tesouros de harmonia que é possível ao homem beber da taça dos deuses? Você estudou essa madeira, essas cordas, esse arco, e principalmente, principalmente, o material de que as cordas são feitas? Você espera reunir, congregar, domar sob seus dedos esse maravilhoso, que há dois séculos resiste aos esforços dos mais dotados, que se queixa que geme sob os dedos deles e que jamais cantou a não ser sob os dedos do imortal Tartini, meu mestre? (Dumas, 1850/2005, p. 26).

Essa fala de Murr nos faz pensar nos mitos que parecem atravessar o uso desses instrumentos clássicos que há séculos vêm sendo utilizados pelos músicos. Faz-nos pensar que, a fim de que um músico toque em uma orquestra sinfônica, são necessários certos anos de prática e domínio. Alberto (2010) afirma que preciso abrir mão de alguns "prazeres" de sua infância e adolescência para um treinamento prático diário e árduo no aprendizado da música. Deve ainda desenvolver a sensibilidade de aprender as exigências estéticas das mais variadas composições advindas de períodos históricos díspares da música. Ciurana e Juan (2009) focalizam especificamente o pianista que, tal qual um ator de teatro, precisa se introduzir em um papel concreto interpretando um personagem em determinada situação -, necessita penetrar em uma obra, traduzindo personagens, sensações, paisagens, sentimentos etc., de acordo com o sentido que seu compositor havia deixado.

Tal contexto leva o pianista a experimentar emoções que devem ser transmitidas ao público, como tristeza, alegria, mistério, coragem, doçura, entre outras, as quais parecem estar implícitas em obras de concertos. No pianista, assim como no violinista, haverá igualmente uma grande exigência com relação ao desempenho em seu instrumento. É preciso apresentar um alto nível técnico, para ser considerado um músico bemsucedido. E essa busca pelo êxito, essa supervalorização do êxito, aparecerá na família e nos âmbitos de formação musical feito um valor que se sobreporá a outros, como desfrutar a música, transmitir emoções e crescer como pessoa e como músico. Pressões excessivas podem surgir, quando um trabalho é centrado em valores como rendimento, eficácia e êxito. $\mathrm{E}$, como em uma grande indústria, as disciplinas individualizarão os corpos das grandes orquestras sinfônicas por uma localização que não os implanta, mas distribui e os movimenta em uma rede de relações. Podemos ver os rearranjos disciplinares do espaço em orquestras. Para descrever essa prática musical, há certa noção de família: uma orquestra é formada por famílias de instrumentos (Borchert, 2009).

Há toda uma organização que tenta favorecer a sonoridade que chega ao público, para que todos possam ouvir com o máximo de clareza os instrumentos. Assim, os músicos são postos na disposição que vimos acima. Cada um tem seu espaço. Todos em frente ao maestro, para que possam vê-lo e obedecê-lo em seus comandos. O maestro controla e é controlado em um panoptismo onde circula certa relação de forças que atravessa o público que aprecia a apresentação e os músicos que são por ele governados. As partituras trazem consigo indícios de um poder-saber. Há um entrelaçamento entre o invisível e o enunciável. Os desenhos da composição transformarão o não visível, que é a música, num enunciado que 
rege os atos que devem ser apresentados pelos músicos.

A música tem peculiaridades com relação ao tempo. Hikiji (2006) escreve que ela possui quatro propriedades fundamentais, no que concerne à música ocidental: duração, intensidade, altura e timbre. $\mathrm{O}$ som de um instrumento tem hora para parar e para continuar. Tais momentos já vêm prédefinidos, quando se executa a obra de um compositor em uma orquestra. Nas peças dos grandes autores que marcaram época na música, todos os acontecimentos são cuidadosamente selecionados, a fim de permitir a construção de uma estrutura densa e bem formatada.

Um tempo que não é só o tempo de trabalho, o tempo dos ensaios, o tempo de duração de uma obra qualquer a ser executada, ou mesmo o tempo de chegada e de saída de cada músico. É um tempo que existe dentro da própria música, dentro de sua estrutura. Um tempo que deve ser seguido quase sempre à risca, preciso. Caso contrário, a orquestra desafina e se perde. A disciplina, como sustenta Foucault (1998), define cada uma das relações que o corpo deve manter com o objeto que manipula. Cada músico terá movimentos próprios, de acordo com seu instrumento, terá uma postura ideal enquanto o executa. Um pianista deve sentar-se em determinado banco, a certa distância do piano, deve manter sua coluna posicionada de maneira "adequada", suas mãos também, assim como um violinista deve manter o violino em determinada posição entre o ombro e o queixo.

Desde o início da aprendizagem prática em seus instrumentos, os músicos terão de aprender essas regras por meio de uma educação rigorosa e disciplinada, de sorte a ampliar a utilidade e a docilidade de seus corpos. Todavia, além da disciplina, a educação musical, em especial no formato de orquestras, pressupõe, na atualidade, entremeios e entrecruzamentos com as práticas sociais disciplinares e com a dramática do trabalho musical em suas nuances e especificidades, singularidades e capturas.
A música se torna uma técnica de subjetivação, de gestão da vida e de regulação securitária, na medida em que permite retirar das ruas e fazer tocar almas e corpos com sons e ritmos, timbres e vozes, instrumentos e composições, melodias e atos coordenados de grupo em espetáculo e em treinos rigorosos, regrando cada detalhe e ao mesmo tempo o todo da orquestra em espaços específicos de teatros e cultura com lugar de artefato a ser consumido, mas, em especial, a ser regulado por normas e governos da conduta com fins utilitaristas para a paz mundial. Por exemplo, basta lermos os documentos da Organização das Nações Unidas para a educação, ciência e cultura, criada em 1946 e ligada ao sistema ONU, para vislumbrarmos inúmeros projetos, programas e propostas em muitos países de como efetuar tal política musical, corporal e de docilização da vida por uma política da utilidade econômica e disciplinar. Tudo objetivando a segurança e à paz, à cultura de redução da violência e para criar a coesão social pela cultura e pelos valores de mercado liberal.

\section{$\mathrm{O}$ ato final?}

O objetivo deste artigo foi fazer uma análise do trabalho de músicos de orquestras, dando ênfase às sinfônicas, de acordo com os escritos de Michel Foucault não apenas a respeito do nascimento da disciplina e da docilização dos corpos no trabalho, mas também pela biopolítica, pelo suplício e pela segurança, na atualidade. Vimos que as grandes sinfônicas aparecem em um contexto de expansão industrial do século XIX e, tal como as grandes fábricas, elas também sofreram mudanças em sua estrutura. Parecem ter herdado as práticas disciplinares oriundas da época clássica, quando se começou a usar os corpos como objeto e alvo de poder. O tempo, o espaço, os movimentos, as posturas, a produtividade, a comunicação, quase tudo parece ter de ser controlado, moldado, para que se torne útil e cada vez mais eficaz. A disciplina produzirá corpos dóceis, submissos, "desenvolvidos". 
Observamos igualmente como a música pode estar em combinação com a gestão da vida, da segurança e da violência da guerra e até mesmo, em nome da paz, como guerra continuada por outros meios. As orquestras seriam arranjos empreendedores e liberais de viver com liberdade e segurança, ao mesmo tempo. Diante de tudo isso, o corpo dos músicos também sucumbe à sua própria prática. Mendes e Morata (2007) realizaram um levantamento bibliográfico de estudos relativos à exposição de músicos aos níveis de pressão sonora decorrentes de sua profissão. Os músicos de orquestras sinfônicas têm um nível de exposição não tão elevado, porém, os autores fazem uma ressalva: deve-se considerar que o contato ocorre durante toda a sua vida profissional, inclusive durante os ensaios individuais.

Conforme Marchiori e Melo (2001), 23 músicos da Orquestra Sinfônica da Universidade Estadual de Londrina são expostos, de 3 a 6 horas diárias, a intensidades sonoras que variam de 93 a 102 decibéis, malgrado o limiar máximo recomendado para a audição humana seja o de 85 decibéis. Diante disso, os músicos em questão relatam o aparecimento de zumbidos em sua audição, assim como a intolerância a sons intensos. Oliveira e Vezzá (2010) escrevem sobre relatos de dor musculoesquelética na prática de músicos de orquestras da região do $\mathrm{ABCD}$ paulista. Trelha et al. (2004) produzirão resultados semelhantes com músicos da Orquestra Sinfônica da Universidade Estadual de Londrina. Ou seja, a dor parece fazer parte do trabalho dos músicos de orquestra.

Ora, sabemos que a música pode produzir escapes e resistências e que suscita ressonâncias que fazem vibrar vidas para além dos contornos disciplinares. Dessa maneira, o governo das condutas e a produção de liberdade não estão dissociados, andam juntos e operam sem exterioridade, na imanência da vida e pela vida, no jogo das disputas de saber e de poder por embates em torno da criação de campos de possibilidade e de liberdade de ser, agir, pensar, inventar, sonhar, sentir e se aventurar em governamentalidades perpétuas que nunca cessam de se deslocar e de nos tocar.

O trabalho vivo é um modo de resistir ao trabalho morto, segundo Schwarcz, que pode fazer os mecanismos disciplinares deslizarem para um diagrama de tornar uma orquestra, os músicos e as apresentações dos mesmos um espetáculo a ser apropriado e apreciado enquanto criação e insurreição. O trabalho musical é uma atividade inventiva também e não apenas submissa e disciplinada em prol da utilidade e da docilidade. No mesmo bojo em que a disciplina forja corpos obedientes e produtivos permite a criação do trabalho vivo enquanto vetor problematizador de uma dramática das existências por meio das artes e das culturas no plural em uma rede diagramática de forças da transformação de uma sociedade e de subjetividades com o trabalho da orquestra e musical.

\section{Referências}

Alberto, M. A. (2010). Como se produz artes em Belém: em cena o grupo de teatro cuíra. Ensaio Geral, 2(3), 102-120.

Borchert, G. (2009). A Orquestra Sinfônica: Uma economia de experiência estética (Dissertação de Mestrado). Universidade Federal Fluminense, Rio de Janeiro, RJ, Brasil.

Ciurana, M., \& Juan, L. C. (2009). Hábitos físicos del pianista: problemas y posibles soluciones. Música y educación, 4(80), 7077.

Deleuze, G. (1992). Conversações. Rio de Janeiro: Editora 34.

Deleuze, G. (2005). Foucault. São Paulo: Brasiliense.

Dumas, A. (2005). O colar de veludo (1850). Porto Alegre: L\&PM Pocket.

Feitosa, L. R. C. (2010). E se a Orquestra desafinar? Contexto de Produção e Qualidade de Vida no Trabalho dos músicos 
da Orquestra Sinfônica de Teresina-Piauí (Dissertação de Mestrado). Universidade de Brasília, Brasília, Brasil.

Foucault, M. (1979). Microfísica do poder. Rio de Janeiro: Graal.

Foucault, M. (1988). História da sexualidade I: a vontade de saber. Rio de Janeiro: Graal.

Foucault, M. (1999a). Vigiar e Punir: a história da violência nas prisões. Petrópolis: Vozes.

Foucault, M. (1999b). Em defesa da sociedade. São Paulo: Martins Fontes.

Foucault, M. (2008a). Segurança, território e população. São Paulo: Martins Fontes.

Foucault, M. (2008b). Nascimento da Biopolítica. São Paulo: Martins Fontes.

Foucault, M. (2010). Estratégia, poder-saber. Ditos e Escritos IV. Rio de Janeiro: Forense Universitária.

Hikiji, R. S. G. (2006) Música para matar o tempo intervalo, suspensão e imersão. Mana, 12(1), 151-178.

Marchiori, L. L. M., \& Melo, J. J. (2001). Comparação das queixas auditivas com relação à exposição ao ruído em componentes de orquestra sinfônica. Prófono, 13(1), 9-12.

Mendes, M. H., \& Morata, T. C. (2007). Exposição profissional à música: uma revisão. Revista da Sociedade Brasileira de Fonoaudiologia, 12(1), 63-69.
Oliveira, C. F. C., \& Vezzá, F. M. G. (2010). A saúde dos músicos: dor na prática profissional de músicos de orquestra no ABCD paulista. Revista Brasileira de Saúde Ocupacional, 35(121), 33-40.

Passos, I. C. F. (2008). Poder, normalização e violência: incursões foucaultianas para a atualidade. Belo Horizonte: Autêntica.

Schwartz, Y. (2000). Trabalho e uso de si. Pro-Posições, 11(2), 34-50. Recuperado de

https://periodicos.sbu.unicamp.br/ojs/index. php/proposic/article/view/8644041

Schartz, Y. (2002). Disciplina epistêmica disciplina ergológica paideia e

politeia. Pro-Posições, 13(1), 126-149.

Recuperado de

https://periodicos.sbu.unicamp.br/ojs/index. $\mathrm{php} / \mathrm{proposic/article/view/8643974}$

Trelha, C. S., Carvalho, R. P., Franco, S. S., Nakaoski, T., Broza, T. P., Fábio, T. de L., ... Abelha, T. Z. (2004). Arte e Saúde: Frequência de Sintomas MúsculoEsqueléticos em Músicos da Orquestra Sinfônica da Universidade Estadual de Londrina. Semina: Ciências Biológicas E Da Saúde, 25(1), 65-72. Recuperado de http://www.uel.br/revistas//uel/index.php/se minabio/article/view/3627/2931 


\section{Dados sobre as autoras:}

- Eric Campos Alvarenga: Psicólogo-UFPA. Mestre e Doutor em Psicologia-UFPA. Professor adjunto I de Psicologia Social do Trabalho-UFPA.

- Paulo de Tarso Ribeiro de Oliveira: Psicólogo, UFPA. Mestre e Doutor em Saúde Coletiva, ENSP-FIOCRUZ. Professor associado III de Psicologia do trabalho, na UFPA. Coordenador do Programa de Pós-graduação de Psicologia, IFCH-UFPA.

- Flávia Cristina Silveira Lemos: Possui graduação em Licenciatura, bacharelado e formação em Psicologia pela Universidade Estadual Paulista Júlio de Mesquita Filho (UNESP - 1999), mestrado em Psicologia pela Universidade Estadual Paulista Júlio de Mesquita Filho (UNESP - 2003) e doutorado em História pela Universidade Estadual Paulista Júlio de Mesquita Filho (UNESP - 2007). Professora de psicologia social/UFPA. Bolsista de produtividade em pesquisa CNPQ PQ2.

\section{Agências de fomento:}

- Conselho Nacional de Desenvolvimento Científico e Tecnológico (CNPQ).

\footnotetext{
Declaração de Direito Autoral

A submissão de originais para este periódico implica na transferência, pelos autores, dos direitos de publicação impressa e digital. Os direitos autorais para os artigos publicados são do autor, com direitos do periódico sobre a primeira publicação. Os autores somente poderão utilizar os mesmos resultados em outras publicações indicando claramente este periódico como o meio da publicação original. Em virtude de sermos um periódico de acesso aberto, permite-se o uso gratuito dos artigos em aplicações educacionais e científicas desde que citada a fonte conforme a licença CC-BY da Creative Commons.
} 